\title{
Experiències amb la tensió superficial
}

Basili Martínez Espinet

bmartine@xtec.cat

IES Miquel Martí i Pol (Roda de Ter)

La finalitat d'aquest treball pràctic és la de donar a conèixer i entendre una mica el fenomen de la tensió superficial en aigua a partir d'uns quants experiments qualitatius. Veurem com depèn de la temperatura, de la salinitat, i de la presència de tensioactius. També comprovarem l'efecte Cheerios (tendència que tenen els objectes flotants petits per atreure's l'un a l'altre). Finalment també veurem quin és l'efecte de la naturalesa de la superfície en la tensió superficial de l'aigua.

\section{Què és la tensió superficial?}

La tensió superficial és un fenomen que fa que la superfície lliure d'un líquid es comporti com una membrana elàstica tensa. Això fa que si posem amb compte alguns objectes (agulla, clip, anella) sobre l'aigua surin encara que siguin molt més densos que ella (fig. 1). També fa que alguns insectes com el sabater (fig. 2) puguin surar. Igualment és la responsable del fenomen de la capil.laritat.

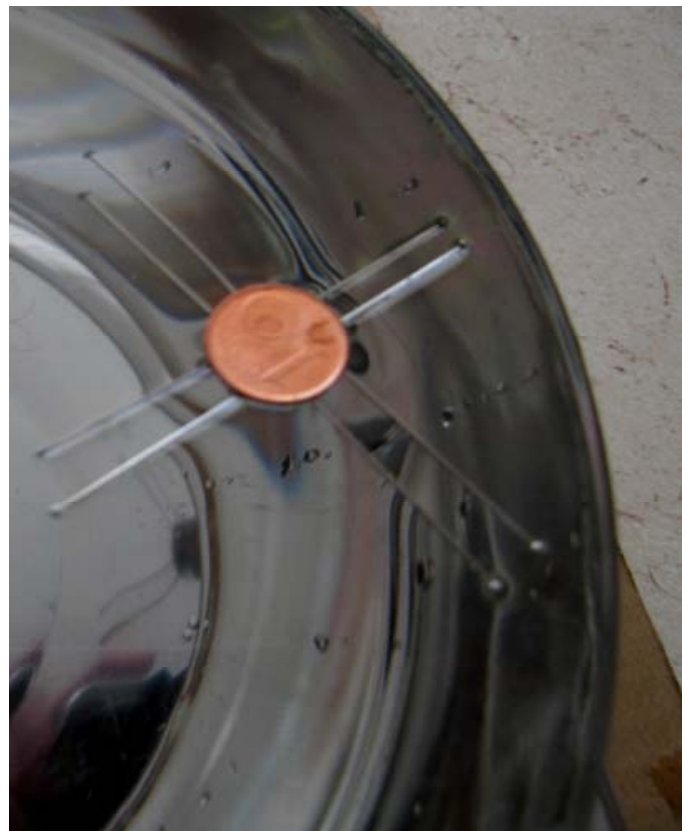

Figura 1. Una moneda de cèntim d'euro, amb un "flotador" fet amb agulles.

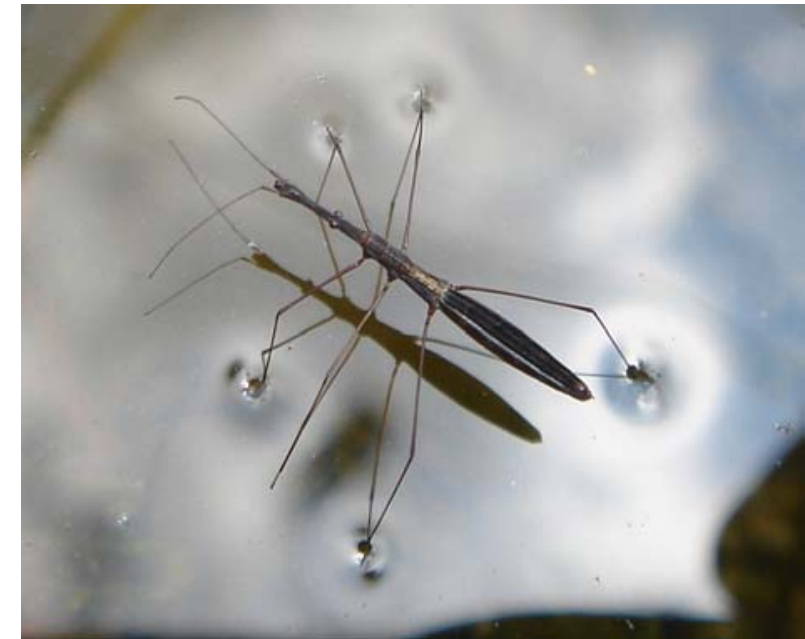

Figura 2. Sabater (Hydrometra stagnorum).

\section{Origen de la tensió superficial}

A l'interior d'un líquid (fig. 3) cada molècula està envoltada per totes bandes d'altres molècules, però no a la superfície ja que no hi té molècules al damunt; això fa que rebi una força neta cap avall.

L'efecte principal d'aquesta força és disminuir al màxim la superfície lliure del líquid, fent que les gotes d'aigua siguin esfèriques (fig. 4) i originant la tensió superficial. 


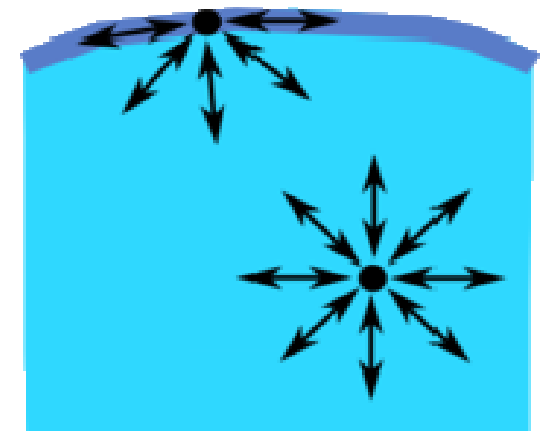

Figura 3. A la superfície del líquid les forces atractives entre molècules no es compensen.

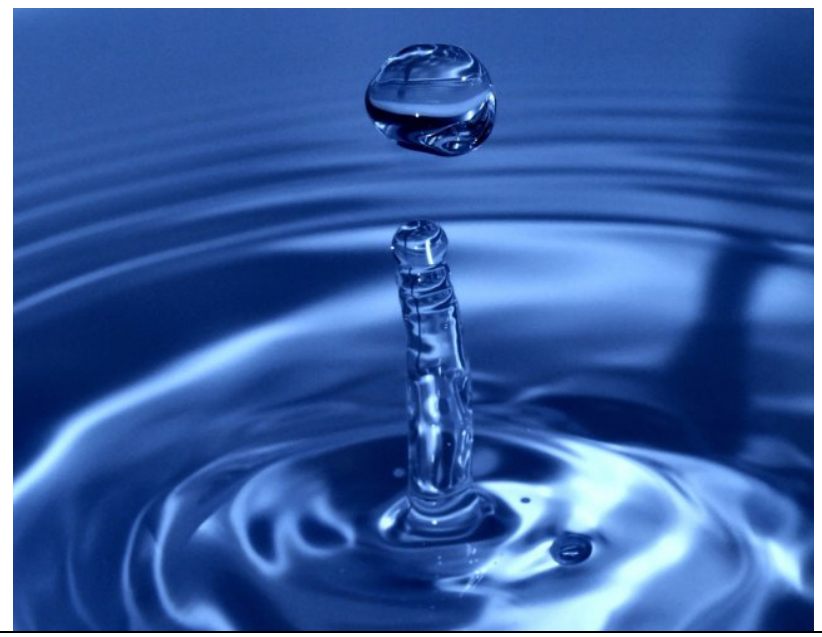

Figura 4. En aquesta imatge podem veure la forma que realment adopten les gotes d'aigua.

\section{EXPERIÈNCIES}

\section{Material}

Agulla, clip, anella (de gruix semblant al clip), fulla d'afaitar, vas de precipitats de $250 \mathrm{~mL}$, fogó elèctric, bol de vidre o cristal-litzador, dos taps d'una llauna de conserva, cera, sabó, sal comuna, pipeta.

\section{Tensió superficial i temperatura}

Agafem el vas de precipitats de $250 \mathrm{~mL}$ i l'omplim fins a sobreeixir d'aigua destil.lada a entre 4 i $7^{\circ} \mathrm{C}$ de temperatura. Pel bec del vas hi introduïm una agulla de cap horitzontalment, agafant-la per la punta i anant amb compte. Veurem com es va orientant cap el nord. Quan ho aconseguim, fem el mateix amb un clip ( que també s'orientarà en la mateixa direcció) i amb l'anella.

Agafem el vas amb compte i el posem damunt del fogó elèctric. Escalfem suaument i observem els canvis.

Si recordem la interpretació de la tensió superficial com una membrana elàstica tensa, veurem clarament què a l'augmentar la temperatura augmenta l'entropia i afebleix l'estructura de la membrana. Aquesta interpretació està d'acord amb els canvis observats.

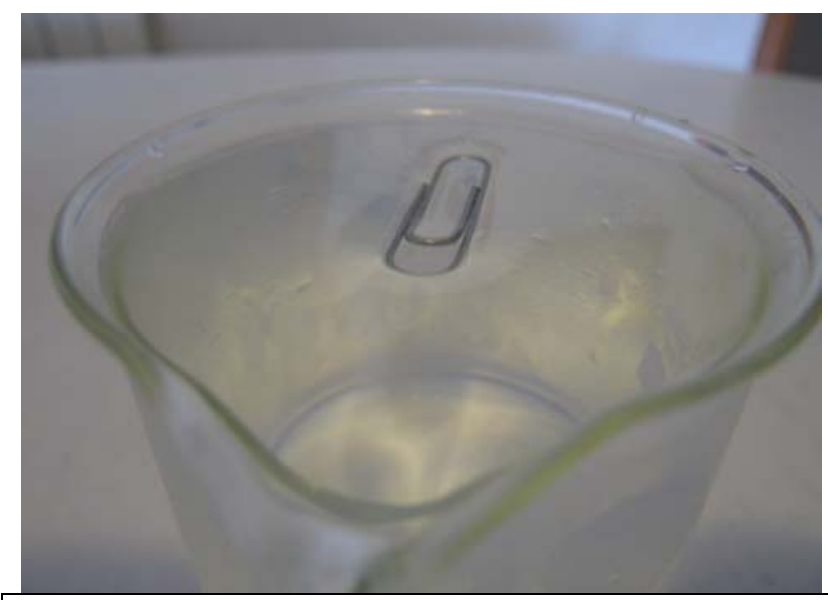

Figura 5. Veiem com el clip s'orienta cap al nord. En el cas de l'agulla observaríem el mateix fenomen.

\section{Tensió superficial i tensioactius}

Repetim el procés anterior però en lloc d'escalfar hi afegim unes gotes de rentavaixelles i observem els canvis.

El tensioactiu fa que la tensió de la malla elàstica que forma l'aigua en la seva superfície disminueixi, i això facilita que pugui envoltar o mullar millor els objectes que hi estan en contacte. Semblant a l'efecte físic de disminuir la constant de la molla $(\mathrm{N} / \mathrm{m})$, que en aquest cas l'anomenem tensió superficial $(\mathrm{N} / \mathrm{m})$, fa que els objectes que abans suraven ara s'enfonsin ràpidament.

\section{Tensió superficial i salinitat}

Preparem amb aigua destil.lada una dissolució de $20 \mathrm{~g} / \mathrm{L}$ de sal comuna. Omplim un vas de precipitats amb aquesta dissolució i un altre amb aigua destilllada. Dipositem un clip i una anella a la superfície de cada un. Posem els dos recipients junts sobre el fogó elèctric, escalfant-los suaument. Fi- 
nalment observem el temps que triga cada un a enfonsar-se (fig. 6).

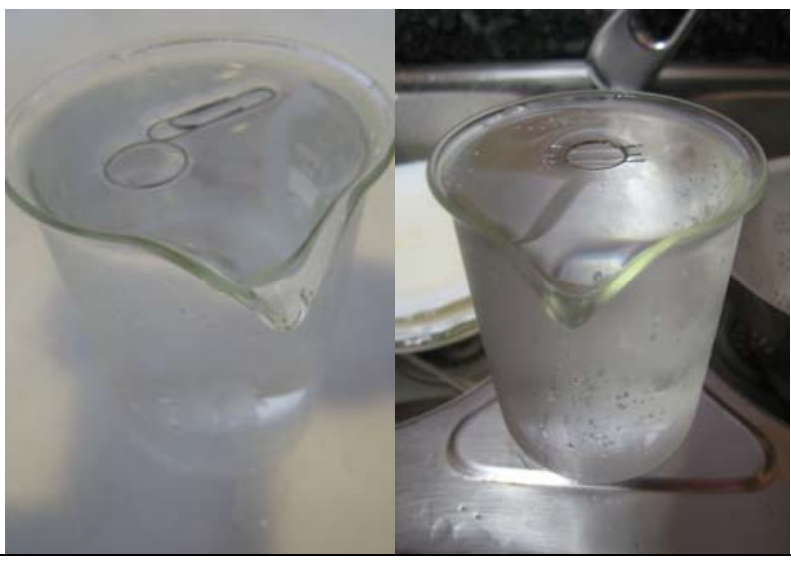

Figura 6. En aquests experiments sobre els efectes de salinitat, temperatura i tensioactius els objectes suren junts (esquera) i s'enfonsen junts. Fins i tot si enganxem agulles a una anella pesant (dreta) podem fer que suri.

\section{Efecte "Cheerios"}

L'efecte Cheerios,com hem dit en la introducció, és la tendència que tenen els objectes flotants petits, a enganxar-se l'un amb l'altre de tal forma que la superfície lliure sigui mínima. Abans d'enganxarse la superfície és més gran que després, de manera que aconseguim que el sistema tingui una energia potencial més baixa.

En un bol de vidre o en un cristal-litzador posem aigua a $4-7{ }^{\circ} \mathrm{C}$ de temperatura fins a sobreeixir. $\mathrm{Hi}$ fem surar en quatre extrems diferents una agulla, una anella, un clip, i una fulla d'afaitar.

A mesura que passa el temps veurem com s'atreuen i que de vegades quan es toquen s'enfonsen. En el vídeo que podeu trobar en el suplement d'aquest número de Ciències, se'n mostren uns exemples (La durada real s'hi ha escurçat).

\section{Naturalesa de la superfície}

Agafem una tapadora metàl-lica d'una llauna de conserva, l'omplim amb cera calenta i la deixem refredar. Quan dipositem aigua freda a sobre amb una pipeta es forma una mena de dipòsit de parets invisibles degut a la tensió superficial.

Agafem una altra tapadora igual però sense la cera. Li afegim aigua freda amb la pipeta fins que comenci a vessar. Si les posem de costat podem observar una diferència de nivell considerable, que es pot mesurar posant un peu de rei al darrera. A la pràctica mesurarem les dues alçades. La de la cera en teoria hauria de ser al voltant de $0,44 \mathrm{~cm}$, però a la pràctica com a molt arribem a 0,4 cm. (A l'annex podem veure aquest càlcul, que es fonamenta en els angles de contacte).

És molt interessant observar el perfil del bassal d'aigua quan l'aigua està sobre la cera i quan esta sobre el metall (fig. 7). Aquest perfil ens dóna l'angle de contacte.

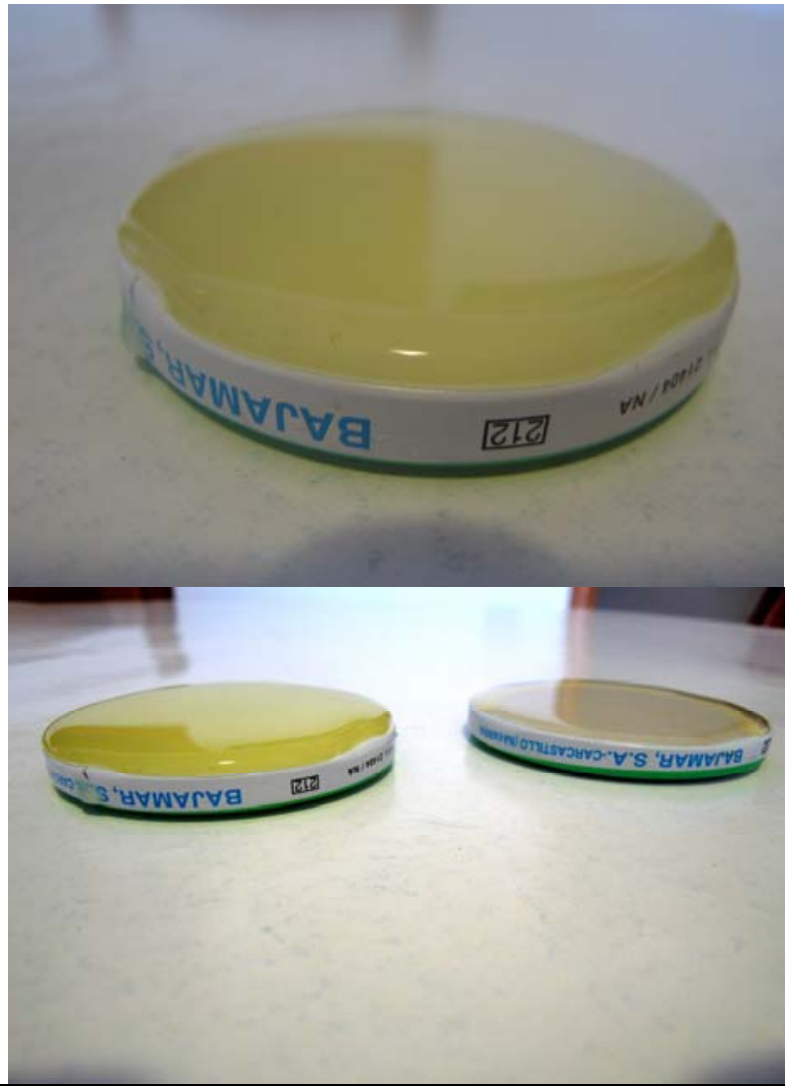

Figura 7. Al la foto de dalt podem veure en detall el dipòsit invisible que produeix la tensió superficial. En la de sota es pot veure la diferència de nivell de l'aigua quan tenim cera a la tapadora o quan no en tenim.

\section{Algunes notes pràctiques}

Aquests experiments funcionen quan deixem una estona el líquid en repòs, i hi dipositem els objectes amb molt de compte.

La tensió superficial també depèn una mica de les forces entre l'aire i la superfície lliure del líquid. És convenient que al laboratori no hi hagi corrents de convecció importants, i que la temperatura ambient sigui baixa.

Si untem els objectes amb una mica d'oli veurem que floten més fàcilment. De totes maneres 
l'experiment funciona perfectament sense utilitzar oli.

La salinitat influeix molt poc en la tensió superficial. Amb aigua de l'aixeta de vegades funciona però altres cops no, ja que conté restes de polielectròlits que s'utilitzen en el seu tractament i disminueixen molt la tensió superficial de l'aigua.

És molt important que la humitat relativa de l'aire sigui baixa per fer les experiències amb èxit!

\section{Conclusions}

Tot i que els experiments són bastant clars, podem pensar unes qüestions per als alumnes per acabar de reforçar el procés d'aprenentatge:

- Com dedueixes que la tensió superficial depèn de la temperatura? En quin sentit?

- Quin és l'efecte del sabó sobre la tensió superficial?

- Busca la tensió superficial de dos líquids que puguin formar ponts d'hidrogen i la de dos que no. Quina conclusió en treus?

- Com explicaries el fet de que les unitats de la tensió superficial siguin les mateixes que la constant de la molla que apareix en la llei de Hooke, tot i ser fenòmens físicament diferents?

- Quina et sembla que és la dependència de la tensió superficial amb la salinitat? Creus que és una dependència molt important? (En aquest cas concret com que la dependència és molt in- significant podem comparar els resultats de tots els grups del laboratori).

- Determina la força pes d'un clip pesant-lo a la balança. Compara aquesta força amb la força de la tensió superficial que ve donada per la fórmula; $F=2 \gamma$ I (on I és la longitud del clip en metres i $\gamma$ és la tensió superficial de l'aigua a $25^{\circ} \mathrm{C}$, que val $0,072 \mathrm{~N} / \mathrm{m}$ ). (En aquest cas veurem que la força de la tensió superficial és més gran que la força pes i l'alumne pot comprovar que el clip encara podria suportar més pes).

- En l'efecte Cheerios, al final els objectes s'atreuen com si fossin imants. Creus que la càrrega elèctrica o el magnetisme, poden tenir-hi res a veure?

- En l'últim experiment de la tapadora encerada també es poden comparar els resultats de les alçades entre els diferents grups per treure conclusions.

\section{BIBLIOGRAFIA}

Luis Vitro Albert (1998). Mecànica de Fluids. Fonaments $I$. Edicions UPC.

Paul. A.Tipler (1980). Física. Editorial Reverté.

http://en.wikipedia.org/wiki/Surface tension

http://www.sc.ehu.es/sbweb/fisica/fluidos/tension/int roduccion/introduccion.htm

http://citt.ufl.edu/Marcela/Sepulveda/html/tension.ht m 


\section{ANNEX: \\ Calculant l'alçada de líquid que sobresurt}

L'amplada o el gruix d'un bassal d'aigua, per un líquid que té un angle de contacte de $180^{\circ}$, ve donat per la fórmula:

$$
\mathrm{h}=2 \sqrt{\frac{\gamma}{g \rho}}
$$

h: Amplada (m)

$\gamma$ : Tensió superficial de l'aigua a $25^{\circ} \mathrm{C}(0,072 \mathrm{~N} / \mathrm{m})$.

$g: 9.8 \mathrm{~m} / \mathrm{s} 2$

$\rho$ : Densitat de l'aigua $(1000 \mathrm{~kg} / \mathrm{m} 3)$.

Si l'angle de contacte és diferent de $180^{\circ}$, hem d'utilitzar la fórmula general:

$$
h=\sqrt{\frac{2 \gamma(1-\cos \theta)}{g \rho}}
$$

On $\theta$ és l'angle de contacte.

En el primer cas, per a l'aigua ens donaria $0,54 \mathrm{~cm}$. En el segon cas, si agafem com a angle de contacte $107^{\circ}$, que és el que surt a la bibliografia per a la parafina o cera i l'aigua, ens donaria 0,436 cm.

En aquesta figura podem veure exemples de diversos angles de contacte: d'esquerra a dreta són de $360^{\circ}$, $180^{\circ}$ i $45^{\circ}$. 